\title{
O SISTEMA TRIBUTÁRIO NACIONAL E A LEI No 13.655/2018: A CONTRADIÇÃO ENTRE A EXIGÊNCIA DE SEGURANÇA JURÍDICA E A INTRODUÇÃO DO CONSEQUENCIALISMO ECONÔMICO NA APLICAÇÃO DO DIREITO TRIBUTÁRIO
}

\author{
THE NATIONAL TAX SYSTEM AND LAW 13,655/2018: THE \\ CONTRADICTION BETWEEN THE REQUIREMENT OF LEGAL \\ CERTAINTY AND THE INTRODUCTION OF ECONOMIC \\ CONSEQUENTIALISM IN THE APPLICATION OF TAX LAW
}

\author{
Flávio Couto Bernardes \\ Pontifícia Universidade Católica de Minas Gerais - PUC Minas - (Belo Horizonte, MG, Brasil) \\ Vinícius Simões Borges Espinheira Fonseca \\ Pontifícia Universidade Católica de Minas Gerais - PUC Minas - (Belo Horizonte, MG, Brasil) \\ Recebimento: 16 maio 2019 \\ Aceitação: 15 jul. 2019
}

\begin{abstract}
Como citar este artigo / How to cite this article (informe a data atual de acesso / inform the current date of access):
BERNARDES, Flávio Couto; FONSECA, Vinícius Simões Borges Espinheira. O Sistema Tributário Nacional e a Lei nº 13.655/2018: a contradição entre a exigência de segurança jurídica e a introdução do consequencialismo econômico na aplicação do Direito Tributário. Revista da Faculdade de Direito UFPR, Curitiba, PR, Brasil, v. 64, n. 3, p. 193-212, set./dez. 2019. ISSN 2236-7284. Disponível em: <https://revistas.ufpr.br/direito/article/view/66896>. Acesso em: 11 mar. 2020. DOI: http://dx.doi.org/10.5380/rfdufpr.v64i3.66896.
\end{abstract}

\begin{abstract}
RESUMO
O presente trabalho trata da alteração legislativa promovida pela Lei $n^{\circ}$ 13.655/2018 no Decreto-Lei $\mathrm{n}^{\circ}$ 4.654/1942. A referida lei acrescentou a este decreto dez novos artigos, todos igualmente pertinentes ao tema da interpretação e da aplicação das normas jurídicas no sistema jurídico brasileiro, especialmente no tocante ao Direito Público. Analisa-se a validade de tal mudança, cotejando-a com a realidade autopoiética do sistema jurídico brasileiro, a qual é garantida por sua norma fundamental - a Constituição da República de 1988 - e na qual se encontra erigido o Sistema Tributário Nacional, de especial interesse ao desenvolvimento do trabalho. Por fim, ante a necessidade de que haja recursividade na argumentação jurídica, e dada a natureza da alteração legislativa, procede-se à verificação acerca de uma possível contradição entre a exigência de segurança jurídica e a introdução do consequencialismo, realizada por intermédio da Lei $n^{0} 13.655 / 2018$, como critério decisório no tocante à aplicação do Direito Tributário.
\end{abstract}

\section{PALAVRAS-CHAVE}

Sistemas sociais. Lei $n^{0}$ 13.655/2018. Análise econômica do direito. Interpretação e aplicação do Direito Tributário. Consequencialismo.

\section{ABSTRACT}

The present paper aims to analyse the amendment promoted by Law 13,655/1208 to the Decreto-Lei (Decree with force of Law) 4,654/1942. The aforementioned law added ten articles to the decree in question, all of which are equally relevant to the interpretation and the application of legal rules in 
the Brazilian legal system, especially in relation to its public law branch. It analyses the validity of such a change, comparing it with the autopoietic reality of the Brazilian legal system, which is ensured by its fundamental rule - the Brazil's Constitution of 1988 - and upon which the national tax system was built, being of especial interest to the development of this paper. Finally, given the need for recursion in legal argumentation as well as the nature of the legislative amendment, a possible contradiction between the requirement of legal certainty and the introduction of consequentialism, carried out by means of the Law 13,655/2018, as a decision-making criterion regarding the application of tax law.

\section{KEYWORDS}

Social systems. Law No. 13,655/2018. Economic analysis of law. Interpretation and application of tax law. Consequentialism.

\section{INTRODUÇÃO}

Intitulado de Lei de Introdução às Normas do Direito Brasileiro (LINDB), o Decreto-Lei no 4.657/1942 é uma norma sobre normas. Com status de lei ordinária, regula o tema da aplicação das normas jurídicas no sistema jurídico brasileiro, estabelecendo, além de parâmetros gerais de elaboração, de vigência e de eficácia, regras acerca de como devem se dar a interpretação, a integração e a aplicação do Direito.

Em 25 de abril de 2018, o então presidente da república sancionou e promulgou a Lei $\mathrm{n}^{\circ}$ 13.655, a qual já recebeu a alcunha de “Lei da Segurança Jurídica” ou “Lei da Segurança para a Inovação Pública”, para alterar a LINDB com a inclusão de enunciados normativos, visando a aumentar a segurança jurídica e a eficiência na criação e na aplicação do Direito Público e, por conseguinte, melhorar a qualidade da atividade decisória no país.

Dentre os dez artigos introduzidos na referida lex legum pela Lei no 13.655/2018, o que interessa ao presente trabalho, que cuidará dos reflexos dessa alteração legislativa na prática judicial envolvendo o Direito Tributário, é especificamente o artigo 20, cujo caput possui a seguinte redação: “Nas esferas administrativa, controladora e judicial, não se decidirá com base em valores jurídicos abstratos sem que sejam consideradas as consequências práticas da decisão.” (BRASIL, 2018).

Sem definir expressamente o que seriam os valores jurídicos abstratos a que faz referência, a “Lei da Segurança Jurídica” prescreve aos órgãos judiciais responsáveis pela aplicação do direito positivo que as suas decisões sejam norteadas não apenas pelo próprio Direito, mas também pelas consequências práticas que possam produzir. Com isso, está-se, em suma, a condicionar a validade do processo decisório judicial à produção de argumentos extra ou metajurídicos de natureza tanto consequencialista quanto probabilística, caso não conferida a devida formatação interpretativa. 
Não obstante o propósito manifesto de promover um estado de segurança jurídica, em verdade o referido enunciado normativo permitiu que o raciocínio jurídico fosse permeado pela consideração de consequências da ordem do ser e, desse modo, abriu uma fissura no sistema jurídico, expondo-o ao seu meio circundante, em especial no tocante à matéria tributária e ao conteúdo do sistema econômico.

Esse raciocínio orientado pelas consequências marca o movimento denominado de Análise Econômica do Direito (AED) (ARAÚJO, 2017, p. 132), que visa a determinar a validade da experiência jurídica a partir de parâmetros econômicos. A AED rejeita não apenas que a tomada de decisões jurídicas seja realizada conforme o Direito, exigindo a referência ao contexto socioeconômico, tal qual o artigo 20 da LINDB, como também rejeita a autonomia do sistema jurídico (SILVEIRA, 2009, p. 13).

Como o Direito é um sistema autopoiético e, portanto, operativamente fechado, mas cognitivamente aberto, que se define modernamente como direito positivo (LUHMANN, 2016, p. 51), não se admitem relações causais entre o sistema jurídico e o seu meio circundante. Isso porque, enquanto sistema operativamente fechado, o sistema jurídico se vale de uma rede própria de operações para produzir o seu sentido específico e, assim, reproduzir-se. A conclusão é que somente o Direito pode dizer o que ele próprio é (LUHMANN, 2016, p. 59, 67).

Diante desse cenário, o presente trabalho tentará verificar se a alteração legislativa em questão é de fato válida no tocante à aplicação do Direito Tributário, em particular, ou se vai de encontro à exigência de fechamento operacional do sistema jurídico, que proscreve qualquer abertura para sistemas ou para critérios de validade metajurídicos sem que haja uma prévia juridicização dos mesmos.

\section{A LEI No $13.655 / 2018$ E A INTRODUÇ̃̃o DO VIÉS PRAGMÁTICO- CONSEQUENCIALISTA TÍPICO DA AED NA APLICAÇÃO DO DIREITO PÚBLICO}

Visando à promoção da segurança jurídica, a Lei $n^{0}$ 13.655/2018 alterou o conteúdo do Decreto-Lei $\mathrm{n}^{\circ}$ 4.657/1942 (LINDB), que cumpre o papel de uma norma de sobredireito, estabelecendo novas diretrizes para a aplicação do Direito Público - no qual se insere o Direito Tributário -, entre as quais a exigência de que os julgadores considerem, antes de decidir os casos 
que se lhes apresentem, as consequências práticas que podem advir de suas eventuais decisões como determinantes nesta atividade, nos termos do artigo 20 da LINDB.

Claramente, a ideia por detrás da inserção do referido enunciado seria a de que, na medida em que as decisões jurídicas impactam o mundo do ser, haveria a necessidade de reforçar a exigência de uma atuação decisória responsável por parte dos órgãos estatais que possuem a competência para interpretar e aplicar as normas de Direito Público, especialmente diante da relativa indeterminação presente na prática jurídica.

Segundo Luís Roberto Barroso (2018, p. 309), no momento da aplicação se encerra o processo de interpretação do Direito, convertendo-se a norma abstrata em norma concreta (norma de decisão), com a pretensão de conformar o ser ao dever-ser.

Dessarte, a pretexto de melhorar a qualidade da atividade decisória no Brasil, a LINDB passa a determinar que, quando da aplicação de normas de Direito Público, o Poder Judiciário não poderá decidir sem levar em consideração as consequências práticas da decisão, as quais passam a ser determinantes para a sua tomada em comparação com as outras decisões que seriam igualmente possíveis do ponto de vista jurídico. Sugere-se, assim, um método empírico de inquirição, ou seja, uma aprendizagem por tentativa e erro, como o melhor para conduzir a aplicação do Direito (POSNER, 2003, p. 9).

Nos termos do novel artigo aqui mencionado, uma decisão que pretenda aplicar o Direito Tributário, seja em favor do contribuinte, seja em favor da Fazenda Pública, para que seja válida conforme a exigência constitucional de fundamentação das decisões (artigo 93, inciso IX, da Constituição da República de 1988), deverá ir além das suas consequências jurídicas e justificar-se com base na previsão de suas prováveis consequências reais, seja para as partes envolvidas no litígio em particular, seja para a sociedade em geral. Algo que, a priori, parece tão somente bastante "natural e intuitivo”, embora não seja próprio da Ciência do Direito (VIARO, 2019, p. 73, 75).

Nesse contexto, vislumbra-se, com bastante facilidade, o potencial de aumento do uso de argumentos consequencialistas de cunho econômico, especialmente por parte da Fazenda Pública, que sempre os utilizou, mesmo antes da promulgação da Lei no $13.655 / 2018$, a pretexto de concretizar o princípio da segurança jurídica.

Por exemplo, no julgamento do Recurso Extraordinário (RE) $n^{0}$ 574.706/PR, quando o Supremo Tribunal Federal (STF) decidiu pela inconstitucionalidade da inclusão do Imposto sobre Circulação de Mercadorias e Serviços (ICMS) na base de cálculo do Programa de Integração Social (PIS) e da Contribuição para o Financiamento da Seguridade Social (Cofins), a Fazenda Pública 
Nacional pugnou pela modulação dos efeitos dessa decisão com base no argumento extrajurídico de que, se ela se desse ex tunc, haveria um impacto negativo de mais de R 250 bilhões ao erário.

O consequencialismo, que não constitui uma posição teórica apriorística e permanente do intérprete, corresponde à utilização de argumentos de consequência na aplicação do Direito para justificar ou fundamentar a decisão tomada (GODOI, 2009, p. 287). Ele consiste basicamente na consideração de como as decisões judiciais influenciam e se projetam sobre a realidade fática diante de um caso concreto específico; por exemplo, em termos econômicos. A depender da resposta a tal consideração, a decisão será classificada como boa ou ruim.

Nos Estados Unidos da América, Adrian Vermeule (2006, p. 5) manifesta-se no sentido de que "os juízes devem interpretar os textos legais de acordo com as regras cuja observância produz as melhores consequências a todos”. No Brasil, Ricardo Lobo Torres (2010, p. 22) afirma que o trabalho do juiz "será, então, o de complementar e integrar o ordenamento, recorrendo ao raciocínio de custo/benefício ou de ponderação de políticas”.

A assunção dessa postura consequencialista perante o sistema jurídico e os efeitos que pode produzir no mundo concreto redunda na aplicação da denominada Análise Econômica do Direito (AED) (FOLLONI; SIMM, 2016, p. 59; VIARO, 2019, p. 76), cuja razão de ser consiste em viabilizar que se prevejam as consequências que podem decorrer da prática jurídica por intermédio do aparato teórico oferecido pela Economia, a qual se preocupa com a solução de problemas de escassez (LUQUE, 2019, p. 139).

Segundo Gary Minda (1995, p. 105), a AED, funcional e adaptável, representa um instrumento associado à vertente do pragmatismo jurídico que crê na possibilidade de uma abordagem flexível e intuitiva da aplicação do Direito. Com efeito, a exigência consubstanciada no artigo 20 da LINDB abre o sistema jurídico à adoção da AED (MATHIS, 2012, p. 3) e, ao fazê-lo, borram-se as fronteiras entre o jurídico e o não jurídico (POSNER, 2003, p. 19).

Conforme a concepção pragmática de aplicação do Direito, o juiz não se encontra obrigado a observar a norma jurídica, dando-lhe eficácia se, e somente se, da sua aplicação resultarem consequências benéficas que se adequem e atendam às necessidades da sociedade que, direta ou indiretamente, possam estar envolvidas no caso concreto (BILHIM, 2016, p. 37). Considerado um dos fundadores da AED (MINDA, 1995, p. 102) e proponente do pragmatismo jurídico, Richard Posner define o cerne do pragmatismo jurídico - apesar da dificuldade inerente a essa tarefa (POSNER, 2003, p. 24) - como sendo uma disposição para fundamentar as decisões em fatos e em consequências (POSNER, 2003, p. 59). 
Nada obstante, se as consequências práticas se tornam a prioridade dos julgamentos, então o próprio Direito torna-se apenas mais um elemento, absolutamente disponível, no processo de formação do convencimento do juiz que, na prática, ao decidir conforme a sua intuição subjetiva, aplicará a “melhor solução” para o caso concreto.

Logo, assumir o consequencialismo como o fim da interpretação jurídica pode dar ensejo a interpretações que são contra legem (DIMOULIS, 2018, p. 93, 154). Richard Posner admite essa possibilidade e afirma que, embora ela possa levar a uma guerra institucional entre o Poder Judiciário e o Poder Legislativo que até mesmo desestabilize o Estado, negá-la seria pior (POSNER, 2003, p. 71).

\section{A AUTOPOIESE DO SISTEMA JURÍDICO POSITIVO BRASILEIRO}

Os argumenta ad consequentia são, indubitavelmente, argumentos extrajurídicos ou não institucionais, na medida em que "fazem apelo a qualquer outro elemento que não o próprio ordenamento jurídico” (ÁVILA, 2003, p. 132) e se encontram fora do sistema jurídico (ROCHA, 2013, p. 192).

Doravante, cumpre ao presente trabalho analisar se o sistema jurídico brasileiro vigente comporta a utilização dessa espécie de argumentos como fundamento das decisões judiciais quando da aplicação do Direito Tributário.

O Direito é um sistema social autopoiético, operativamente fechado e autorreferencial, cuja função é regular as relações intersubjetivas em sociedade. Ele, enquanto subsistema do sistema social, é descrito por Niklas Luhmann (2016, p. 32) como um "sistema que se auto-observa e se descreve, e, portanto, desenvolve suas próprias teorias, procedendo de modo 'construtivista', ou seja, sem qualquer tentativa de representar o mundo exterior no sistema”.

Nada obstante, o sistema normativo-jurídico é cognitivamente aberto, retirando dos demais sistemas, tais quais o moral e o econômico, os dados que consubstanciam a matéria social que preenche as formas normativas (VILANOVA, 2015, p. XII). Ao tratar do Direito sob a perspectiva da teoria sistêmica luhmanniana, Marcelo Neves (2006, p. 81) aduz que, conquanto operativamente fechado, “a escolha entre lícito e ilícito é condicionada pelo ambiente”, uma vez que o Direito assimila os fatores do meio circundante (ambiente), a seu tempo e modo, jamais se deixando influenciar diretamente por tais fatores.

O conceito de autopoiese garante ao sistema jurídico a sua permanência por meio de uma estabilidade dinâmica. Em sendo assim, eventuais mudanças nas estruturas do Direito, tal qual a 
promovida pela Lei $\mathrm{n}^{0} 13.655 / 2018$, só podem ser concebidas se elas puderem ser utilizadas pelo próprio sistema para executar sua autopoiese. Isso porque a aplicação do Direito (operação) pressupõe estruturas que lhe sejam internas (normas), a fim de que, por meio de referências recursivas a estas, ele possa se autodeterminar e permitir a continuidade de suas operações, que são igualmente internas, realizando-se assim a autopoiese do sistema jurídico (LUHMANN, 2016, p. 67).

Com efeito, o sistema jurídico regula abstratamente situações concretas. Todavia, fá-lo por intermédio de esquemas típicos em que se consubstanciam as notas típicas que ele próprio pretende selecionar a partir do ambiente social (VILANOVA, 2010, p. 283). Desse modo, os únicos fatos que são relevantes para o funcionamento do sistema são os que foram juridicizados.

Acertadamente, Heleno Taveira Torres (2011, p. 22) afirma que a "tributação é uma realidade jurídica e esta incide sobre situações jurídicas”, porquanto toda a “experiência jurídica é uma experiência normativa” (BECKER, 2018, p. 63). Então, ao valorar os fatos e as condutas por meio de sua inserção em uma norma jurídica, juridicizando-os, a sociedade visa a organizar o convívio social para permitir a coexistência pacífica entre os seus integrantes (BERNARDES, 2006, p. 28).

Por sua vez, Niklas Luhmann (2016, p. 56) está certo de que o Direito adquire sua realidade exclusivamente por meio de suas operações próprias, as quais produzem e reproduzem o sentido específico do Direito. Afinal, são as normas jurídicas que definem os fatos que são relevantes e que teriam ocorrido para fins de aplicação do Direito (NOBLES; SCHIFF, 2006, p. 153; VILANOVA, 2015, p. 25).

Não há dúvida de que a Constituição é a estrutura normativa que permite a, e ao mesmo tempo resulta da, autonomia operativa do sistema jurídico, assegurando-lhe o seu fechamento e permitindo-lhe filtrar, por meio de critérios próprios, os elementos que, oriundos de sistemas externos, terão validade no interior do Direito apenas mediatamente. Marcelo Neves (2006, p. 100) esclarece a questão quando afirma que a "normatividade constitucional fixa os limites da capacidade de aprendizado do direito".

A Constituição da República de 1988, situada no ápice do sistema de proposições normativas que é o Direito, é a norma fundamental do sistema jurídico brasileiro em vigor. Além de assegurar o fechamento operativo deste, opera como o critério unificador da ordem jurídica. Cumpre reproduzir a lição de Lourival Vilanova acerca do papel da constituição:

Não é tão-só por via lógica que se põe a norma fundamental (pressuposta) ou a norma constitucional material (positiva) como nível mais alto. É também por exigência ontológica. O ser do Direito mostra uma estruturação em planos normativos. A norma de investidura, 
aquela que confere autoridade ou titularidade de órgão a um indivíduo para editar normas, antepõe-se às demais normas. É norma-de-norma, norma que dispõe sobre o processo de construção e de transformação (em termos sintáticos; dogmaticamente, fala-se em produção ou criação de normas). Sem a norma, cujo pressuposto descreva o primeiro fato, como fato jurígeno, como fato fundamental (Grundfaktum ou suporte fáctico inicial), nenhum sistema jurídico-estatal se constitui, para tomarmos a teoria kelseniana. (VILANOVA, 2010, p. 271272).

Dessarte, a fim de guardar uma relação de pertinência para com o sistema jurídico, todo e qualquer ato de decisão de criação de normas jurídicas deve atender aos critérios de validade da constituição, a qual estabelece tanto a ordem de validade das fontes normativas, quanto a hierarquia das normas que provêm delas.

Tudo o que se disse até o momento, na medida em que se trata de um subsistema do sistema normativo-jurídico geral, aplica-se ao Direito Tributário, que também possui natureza autopoiética e, portanto, opera de forma fechada, impedindo que se estabeleçam quaisquer relações causais entre ele e os demais sistemas, como o econômico, que se inserem no mesmo ambiente.

Apesar de seu fechamento, há um acoplamento operativo entre o sistema do Direito Tributário e o sistema da Economia, já que a realidade daquele é construída, essencialmente, a partir de fatos cujo conteúdo pertence à realidade econômica. Nesse sentido, a análise realizada por Paulo de Barros Carvalho é cirúrgica:

\begin{abstract}
No âmbito destas investigações, chegaremos à conclusão de que toda construção de linguagem pode ser observada como jurídica, econômica, antropológica, histórica, política, contábil etc.; tudo dependendo do critério adotado pelo corte metodológico empreendido. Existe interpretação econômica da realidade jurídica? Sim, para os economistas. Existirá interpretação contábil dela? Certamente, para o contabilista. No entanto, uma vez assumido o critério jurídico; e claro, terá natureza jurídica, não econômica ou contábil, entre outras matérias. Como já anotado, o direito não pede emprestado conceitos de fatos para outras disciplinas. Ele mesmo constrói seu universo, seu objeto, suas categorias e unidades de significação. (CARVALHO, 2015, p. 231).
\end{abstract}

A fim de que se assegure a autonomia do Direito, padrões oriundos de outros sistemas sociais como, por exemplo, o econômico, não podem orientar a aplicação do Direito, impondo-se a exigência de metodologia rigorosa que adstrinja a concretização da interpretação e da aplicação de normas jurídicas a termos igualmente jurídicos (BALEEIRO, 2013, p. 145; TORRES, 2011, p. 74).

Dessarte, no tocante à tomada de decisões, cumpre ressaltar que considerando a estrutura estratificada do sistema jurídico, Hans Kelsen afirmou que a interpretação e a aplicação do Direito resultam de uma relação de determinação que se estabelece entre uma norma de escalão superior e outra de um inferior da mesma ordem jurídica. Isso se dá porque a norma superior vincula o ato por meio do qual a norma inferior será produzida, determinando-lhe não só o processo pelo qual é posta, mas, eventualmente, o seu conteúdo também (KELSEN, 2006, p. 388). 
Ressalta-se que essa vinculação, todavia, não é completa, porque a norma superior não determina todos os aspectos da norma inferior e, em assim sendo, o ato de aplicação do Direito seria sempre, em alguma medida, indeterminado, o que implica, intencional ou não intencionalmente, “uma margem, ora maior ora menor, de livre apreciação, de tal forma que a norma do escalão superior tem sempre, em relação ao ato de produção ou de execução que a aplica, o caráter de um quadro ou moldura a preencher por este ato” (KELSEN, 2006, p. 388).

Desse modo, em todos esses casos Hans Kelsen (2006, p. 390) é categórico ao afirmar que “oferecem-se várias possibilidades à aplicação jurídica”, ou seja, o Direito a aplicar apresenta-se como uma moldura dentro da qual há várias possibilidades de aplicação, sendo conforme o Direito todo ato que se mantenha dentro dessa moldura e, mais do que isso, "que preencha esta moldura em qualquer sentido possível” (KELSEN, 2006, p. 390).

O fechamento operativo não é assegurado apenas pela aplicação do código-diferença legal/ilegal, mas também pela restrição formal daquilo que se pode considerar como pertencente ao próprio sistema jurídico (NOBLES; SCHIFF, 2006, p. 156). Somente assim garantir-se-á a segurança jurídica pela técnica de aplicação do Direito.

\section{A APLICAÇÃO DO DIREITO TRIBUTÁRIO E A EXIGÊNCIA CONSTITUCIONAL DE SEGURANÇA JURÍDICA}

O conceito-chave para a consecução do presente trabalho consiste no fechamento operacional de que goza o sistema jurídico-tributário enquanto sistema autopoiético, isto é, um sistema que define seus próprios conteúdos e critérios de validade, reproduzindo-se por meio de operações autorreferenciais.

Diante da natureza dos sistemas jurídicos alinhavada supra, à qual pertence, por suposto, o Direito Tributário, igualmente insta que se analise se a alteração legislativa promovida pela Lei ${ }^{\circ}$ 13.655/2018 na LINDB, especificamente a inclusão do já referido artigo 20, é de fato válida no tocante à aplicação do Direito Tributário, em particular, ou se vai de encontro à exigência de fechamento operacional do sistema jurídico.

Nesse sentido, o fechamento operativo não é assegurado tão somente pela aplicação do código-diferença legal/ilegal, mas também pela restrição formal daquilo que se pode considerar como pertencente ao próprio sistema jurídico (NOBLES; SCHIFF, 2006, p. 156).

Logo, a interpretação e a aplicação do Direito, enquanto operações do sistema jurídico, devem ser restritas ao Direito filtrado pelo Direito, isto é, aos processos comunicativos próprios e 
exclusivos do sistema jurídico, a fim de que este garanta a segurança jurídica aos cidadãos. Garantila significa evitar potenciais conflitos entre os cidadãos e, para tanto, estes precisam ter certeza quanto às consequências que foram atribuídas às suas condutas pela ordem jurídica (BERNARDES, 2006, p. 28).

O sistema jurídico, enquanto sistema da sociedade, constrói sua versão do interesse deste ambiente - a sociedade - em “um interesse na confiabilidade, na uniformidade, na predicabilidade e na imparcialidade da administração da justiça” (LUHMANN, 2016, p. 527), e tem a responsabilidade de regulamentar a própria mutabilidade.

Como dificilmente se podem prever as situações futuras de aplicação da lei, faz-se mister “prover a legislação e a vinculação do juiz à lei” (LUHMANN, 2016, p. 53, 79).

Dessa forma, se se deve exigir de quem julga a justificação de sua decisão, não se pode admitir que, nesse mister, utilize-se de todo e qualquer tipo de argumento, como o das consequências práticas, na medida em que apenas os argumentos que possam ser referenciados ao próprio Direito gozam de validade para tanto.

Afinal, uma comunicação só é jurídica se se ordena conforme a função do sistema jurídico, qual seja, a de prover segurança jurídica, bem como se entra no domínio de sua codificação binária que se dá em termos de lícito e de ilícito (LUHMANN, 2016, p. 81).

Com efeito, outro caminho deve ser buscado para tratar da presente questão acerca da atividade decisória. Um trajeto que prescinda de recorrer a elementos extrajurídicos e, portanto, adeque-se à realidade específica do direito brasileiro.

Tal caminho não será relevado por uma teoria da argumentação qualquer, que possa eventualmente levar à abertura e ao consequente colapso do sistema, mas, sim, por uma que se mostre adequada à realidade do direito brasileiro, evitando que uma racionalidade substantiva tome conta do processo decisório judicial e, com isso, o componente retórico no raciocínio de fundamentação da decisão recrudesça ao estilo da política que se tenta agradar, como adverte Niklas Luhmann (2016, p. 532).

O discurso de aplicação, que é essencialmente jurídico, e o de fundamentação, por sua vez, político, possuem escopos distintos e, por isso, não podem ser confundidos, sob pena de ruir a complementaridade que guardam entre si (CRUZ; SALDANHA, 2015, p. 63).

Além disso, essa vinculação do juiz à lei é inerente à realidade do sistema jurídico, uma vez que a argumentação jurídica é espécie de argumentação institucional e, ipso facto, vincula-se às regras e aos procedimentos previamente estabelecidos, sem se preocupar com razões de natureza moral, política ou econômica (SHECAIRA; STRUCHINER, 2016, p. 37). 
Consigne-se que, de matriz romano-germânica, o direito tributário brasileiro é uma totalidade estrutural e funcional que expressa em si mesma o princípio da segurança jurídica (TORRES, 2011, p. 18), em que a lei escrita e estrita é ponto de partida da experiência jurídica. Sagram a normatividade da legalidade, pelo que não se pode exigir tributo sem que antes a lei o estabeleça, não se admitindo que sua interpretação ou sua aplicação sejam norteadas por consequências práticas. Decorrência lógica do Estado de Direito, o princípio da legalidade permeia todo o Direito Público, especialmente o Direito Tributário (BERNARDES, 2006, p. 201).

A atividade daquele que aplica o Direito deve, necessariamente, reconduzir-se à lei e ao próprio Direito (ÁVILA, 2005, p. 288) e, no que diz respeito a especificidades do sistema jurídico brasileiro, cumpre ressaltar o relevo de que goza o Direito Tributário nele. Conforme a observação feita por Sacha Calmon Navarro Coêlho (2016, p. 216), “país algum ‘constitucionalizou’ tanto o Direito Tributário”, e a constituição é “o conjunto de normas de hierarquia mais elevada em um sistema jurídico (MACHADO, 2015, p. 54).

O Direito Tributário consubstancia em suas normas verdadeiras limitações ao poder de tributar estatal. Acerca de sua natureza, Aliomar Baleeiro (2010, p. 2) já esclareceu que o sistema do Direito Tributário “movimenta-se sob complexa aparelhagem de freios e amortecedores, que limitam os excessos acaso detrimentosos à economia e à preservação do regime e dos direitos individuais”.

Por isso, no âmbito do Direito Tributário a utilização de argumentos consequencialistas é questão muito delicada, já que o fato jurídico da tributação está diretamente atrelado aos setores econômicos e financeiros da sociedade e, portanto, aos fatos sociais, econômicos e financeiros.

O arcabouço constitucional do Direito Tributário ratifica o compromisso do Estado Democrático de Direito, que foi erigido pela Constituição da República de 1988 com a promoção da segurança jurídica, essencial à concretização dos direitos e das liberdades fundamentais em favor de todos os brasileiros.

Inegável que é caro ao direito moderno, e não uma exclusividade do direito brasileiro, ser racional e trazer segurança, ou seja, permitir a previsibilidade em relação aos comportamentos humanos, sobretudo os relativos à atividade econômica.

Oponente da aplicação consequencialista do Direito, Niklas Luhmann compreende a atividade decisória como condicionada pelos programas normativos positivados pelo legislador competente. Coincidentemente, Sacha Calmon Navarro Coêlho (2015, p. 577) afirma que a norma jurídica tem um ponto de partida legislativo e um ponto de chegada jurisdicional. Se não fosse assim, o Direito não cumpriria sua função de estabilização das expectativas normativas da sociedade. 
Afinal, para que seja possível reconhecer o que é Direito, é preciso que se possa distingui-lo do que não é Direito, o que ocorre apenas quando há referências recursivas de operações jurídicas a operações igualmente jurídicas (LUHMANN, 2016, p. 35, 76).

Klaus Mathis (2012, p. 7) reconhece que Niklas Luhmann compreende a aplicação do Direito como uma operação estruturada sob a forma do programa hipotético-condicional, em que, se $A$ (hipótese de incidência) é, deve ser $B$ (consequência jurídica), assemelhando-se, pois, à de Hans Kelsen.

A Constituição é a referência interna do sistema jurídico que condiciona a validade da atividade de interpretação e de aplicação do Direito, permitindo a controlabilidade dos seus critérios de validade. Ela o faz estatuindo as fontes e os métodos de produção normativa, assim como a ordem de validade das fontes e a hierarquia das normas daquelas fontes provenientes (VILANOVA, 2010, p. 275).

A parametricidade na aplicação do Direito Tributário assegura a compatibilidade material das normas inferiores em relação às superiores e, por conseguinte, a coerência interna do sistema, levando-o a uma situação de permanência e de continuidade perante o ambiente em que se insere.

Conquanto não se negue a existência de consequências práticas das decisões judiciais, para o Direito, que opera seletivamente juridicizando os fatos sociais que lhe são relevantes e desjuridicizando os que não o são, apenas as consequências jurídicas importam (VILANOVA, 2015, p. 27).

Considere-se a norma jurídico-tributária que estabelece a obrigação principal de pagar tributo: a sua hipótese de incidência é a abertura do sistema tributário à realidade fática e o consequente normativo, ao irradiar seus efeitos, transforma-se em fato (VILANOVA, 2015, p. 28).

Para além de qualquer dúvida, esta, quando consubstanciada no consequente normativo de uma regra-matriz de incidência tributária, corresponde à instauração da obrigação tributária.

Então, para a aplicação do Direito, esta entendida como o momento de atuação dinâmica da norma jurídica, importa apenas a irradiação de sua eficácia jurídica, a qual implica a instauração de uma relação jurídica entre o contribuinte e o Estado, cuja respeitabilidade será averiguada pelo Poder Judiciário.

Nesse sentido, cumpre reproduzir a ressalva feita por Alfredo Augusto Becker (2018, p. 71), de que a incidência da norma jurídica e os respectivos efeitos jurídicos independem da atuação do Poder Judiciário, cuja função consiste apenas em verificar e assegurar a respeitabilidade àqueles mesmos efeitos. 
Na conclusão do silogismo normativo, a saber, na decisão que aplica o Direito, dá-se a determinação normativa, esta entendida como a indicação de forma individualizada dos elementos que compõem os âmbitos de incidência - material, pessoal, temporal e espacial - da norma individual que figura na conclusão do silogismo.

Então, especificamente quanto à aplicação do Direito Tributário, quando ocorre a verificação da ocorrência do fato juridicamente relevante no mundo do ser (hipótese de incidência), instaura-se a obrigação tributária (relação jurídica) em função da qual o Estado (sujeito ativo) passa a ser credor do tributo (objeto relacional), devido pelo contribuinte (sujeito passivo).

Diante dessa realidade do sistema jurídico, menos plausível parece ser a realização da exigência de consideração das consequências práticas no momento da aplicação do Direito (PISCITELLI, 2011, p. 22), conforme o artigo 20 da LINDB. Niklas Luhmann (2016, p. 496) já considerara esse problema e acerca dele afirmou que "uma ponderação abstrata de valores deve se justificar a partir do texto, já que de outra maneira ela não teria, em termos jurídicos, nem pé nem cabeça”.

Em um sistema jurídico, cuja estrutura é estratificada, é absolutamente natural que as normas de escalão superior vinculem a produção e o conteúdo de normas de outro escalão inferior, segundo a relação silogística do programa hipotético-condicional “se, então”. A verificação da coerência entre o direito vigente e a decisão de fato tomada é permitida pelo silogismo da aplicação (MACCORMICK, 2005, p. 203). Afinal, ainda que o juiz de fato proceda à análise das consequências concretas de suas decisões, ela "não pode jamais suprimir o caráter deontológico do provimento jurisdicional” (CRUZ; SALDANHA, 2015, p. 65).

Essa não poderia se dar de forma diversa, porque a norma fundamental não admite qualquer contradição entre ela e as demais normas jurídicas que pertençam ao mesmo sistema que ela (TORRES, 2011, p. 94). Assim, o jurista deve visar à possibilidade de realizar um julgamento de validade acerca da aplicação da norma ao caso concreto, cotejando-a com o direito positivo vigente, sendo essa uma das razões de ser da teoria kelseniana da moldura normativa, conforme exposto por Stanley Paulson (1990, p. 148).

Portanto, ao refutar a possibilidade de que, por intermédio da AED, o referido método pragmatista de aplicação do Direito encontre as necessárias condições de aplicabilidade no direito tributário brasileiro, tem-se em mente a advertência de Niklas Luhmann (2016, p. 451) de que, para que se compreenda a argumentação jurídica, "é decisivo, antes de tudo, compreender o que argumentos não podem alcançar e o que eles não podem produzir" e, nesse sentido, "nenhum argumento pode alterar o símbolo da validade do direito”. 
Diante disso, não se está a questionar se as ferramentas propostas pela AED contribuiriam para a melhor clareza da aplicação do sistema jurídico e das respectivas consequências, mas se tais aspectos econômicos poderiam e, em caso positivo, de que modo ou em que medida determinariam o modelo de interpretação jurídica, sem olvidar a necessidade de concretização da segurança jurídica.

Desse modo, tem-se que uma decisão bem justificada seria aquela que, além de consistente e coerente em relação ao sistema jurídico, é aceitável em suas consequências e, se a medida de aceitabilidade das consequências pode ser estabelecida considerada a função do sistema jurídico, o único critério possível seria a redundância, porque somente as boas razões tornam operativa a consistência do sistema (LUHMANN, 2016, p. 498).

Afinal, o processo de justificação é uma operação completamente interna do sistema jurídico e inerente à tomada de decisão, sendo a função do intérprete construir o sentido da norma jurídica dentro dos limites do sistema jurídico para, se for o caso, aplicá-la na situação concreta. Logo, Niklas Luhmann (2016, p. 492) afirma que o "pensamento selvagem que se encontra fora do direito não pode reivindicar relevância alguma”.

Ainda nesse sentido, não se deve atribuir o fardo da responsabilidade pelas consequências práticas aos órgãos responsáveis pela aplicação do sistema jurídico, especialmente os tribunais, porque "os juízes não dispõem nem de meios, nem da disposição para correr riscos, condições necessárias à busca de fins” (LUHMANN, 2016, p. 506). Essa responsabilidade deve recair sobre os órgãos de representação política do povo, que correm os correspondentes riscos políticos, sob pena de essa antevisão das consequências práticas confundir programas de fins políticos com decisões jurídicas (LUHMANN, 2016, p. 506, 507).

Logo, o risco de se proceder à desdiferenciação do sistema jurídico por meio da abertura trazida pelo artigo 20, caput, do Decreto-Lei $n^{\circ} 4.657 / 1942$, tal qual enunciado pela Lei $n^{\circ}$ 13.655/2018, é patente, porquanto introduz a exigência de que, em sede de aplicação, o Direito Tributário se comunique em termos econômicos, e a interpretação econômica do Direito facilita, quando mesmo não implica, esse processo de desdiferenciação sistêmica (CRUZ; DUARTE, 2013, p. 109, 197), o que resultaria, em última instância, com a dissolução do caráter determinável de suas estruturas (LUHMANN, 2016, p. 31), na transformação do Direito em Economia (DIMOULIS, 2018, p. 90). 


\section{CONSIDERAÇÕES FINAIS}

No que diz respeito ao Direito Tributário (ROCHA, 2013, p. 191), a Fazenda Pública sói utilizar-se do argumento estritamente econômico de que o erário não tem condições de fazer frente à despesa decorrente da imposição legal de restituição dos tributos indevidamente recolhidos, nem de renunciar ao recolhimento dos tributos, ainda que, em ambos os casos, esteja-se diante de uma tributação inválida, seja porque inconstitucional, seja porque ilegal.

Se a consideração de consequências econômicas for determinante para aferir a validade de uma decisão judicial, então toda tributação, ainda que seja declarada inconstitucional, deverá ser protegida, na medida em que a falta de cobrança de um tributo ou a sua restituição ao contribuinte sempre implicará perda de receita para o Estado, afetando-lhe a atividade financeira, o que, em última instância, ensejará até mesmo a alteração de precedentes anteriormente firmados em desfavor da Fazenda Pública (TORRES, 2010, p. 47).

De mais a mais, a se persistir em seguir por esse caminho, inevitavelmente o instituto jurídico da modulação de efeitos terminará se transformando em mais um instrumento de arrecadação à disposição do Estado e em detrimento dos direitos e das liberdades fundamentais dos cidadãos.

No limite, admitir a interveniência desse tipo de situação na aplicação do Direito Tributário implica uma autorização ao Estado para manter leis tributárias inconstitucionais e, desse modo, também a subversão da segurança jurídica, que estaria sendo utilizada para sustentar a restrição dos direitos fundamentais de liberdade dos cidadãos (ÁVILA, 2016, p. 564).

A impossibilidade de o Estado ser negativamente surpreendido, dado que ele próprio, por meio do seu Poder Legislativo, é o responsável pela produção do direito a ser aplicado, afasta a tese de que a segurança jurídica visaria à proteção do Estado. Como afirma Humberto Ávila (2016, p. 565), em matéria tributária o princípio da segurança jurídica é norma objetiva em favor do cidadão.

Dessa forma, dado o status constitucional dos direitos e garantias fundamentais, restringilos por meio de elemento fático não integrante do consequente normativo da regra-matriz de incidência tributária - o que, per se, já seria juridicamente inválido -, cujo assento é infraconstitucional, é inconcebível.

Essa situação de especulação legal deve ser prontamente neutralizada pelo sistema jurídico, não se admitindo a tentativa de equiparar o objetivo de evitar que o Estado sofra um prejuízo financeiro em função da declaração de inconstitucionalidade de uma norma de incidência tributária, seja pela perda de receita, seja pela restituição, ao dever de promoção da segurança jurídica. 
O argumento consequencialista lastreado nas necessidades financeiras do Estado não é válido para fundamentar uma decisão jurídica, seja a respeito da validade (constitucionalidade) de determinado ato normativo, seja para justificar a eventual modulação de seus efeitos. Ele não se encontra dentro da realidade jurídica. Uma boa razão de decidir deve estar sempre presente como interpretação possível de um texto normativo (LUHMANN, 2016, p. 513).

Ademais, o Estado brasileiro deve, a todo o tempo, zelar pela validade das normas jurídicas que produz, prestando contas de sua atividade à sociedade que o institui. Segundo Luís Eduardo Schoueri (2018, p. 549), o interesse público é revelado exclusivamente pela decisão do legislador e deve prevalecer sobre a vontade e a conveniência do sujeito ativo. Por isso, vale a afirmação de Roque Antonio Carrazza no sentido de que:

Nem mesmo o objetivo, em tese louvável, de solucionar os "problemas de caixa” das pessoas políticas tem força bastante para subverter os princípios fundamentais do sistema constitucional tributário brasileiro, que deitam raízes, em última análise, no próprio princípio da segurança jurídica (CARRAZZA, 2015, p. 585).

Logo, não se deve admitir que ocorra o condicionamento da validade de uma decisão judicial ao grau de conformidade que esta possa ter em relação aos efeitos econômicos que, sob o ângulo da Economia, possam ser considerados desejáveis. Em outros termos, não é admissível que a aplicação válida seja infirmada por suas consequências práticas, futuras e apenas prováveis.

Tratando-se o sistema jurídico de uma estrutura de normas estratificada, é absolutamente natural que as normas de escalão superior vinculem a produção e o conteúdo de normas de escalão inferior. Nesse sentido, a exigência do artigo 20 da LINDB, ao abrir o sistema a considerações extrajurídicas, viola o fechamento operativo consubstanciado nos critérios de validade estabelecidos pela Constituição da República, não podendo ser reconhecida como juridicamente válida.

Nada obstante, ainda que se superem as questões concernentes à natureza autopoiética e à estrutura estratificada do sistema jurídico, o que não parece possível conforme a exposição realizada pelo presente trabalho supra, e se admita que a LINDB poderia ter determinado aos juízes que levassem em consideração as consequências práticas que tivesse prévia e expressamente especificado (MATHIS, 2012, p. 6), este não é o caso, na medida em que a alteração promovida pela Lei $n^{\circ}$ 13.655/2018 foi deveras genérica, o que torna a sua observância, no mínimo, problemática e, portanto, fonte de insegurança.

Sem critérios preestabelecidos normativamente para nortear a atividade decisória, resta ao julgador o exercício ou de sua intuição ou de seu arbítrio. Em outros termos, verifica-se uma 
contradição entre a exigência de segurança jurídica e a introdução do consequencialismo econômico, realizada por intermédio da Lei nº 13.655/2018, no momento de aplicação do Direito Tributário.

Por todo o exposto, a exigência de que os órgãos responsáveis pela aplicação do Direito Tributário, ao decidir as controvérsias que se lhes apresentam, levem em consideração as consequências práticas de suas possíveis decisões - um verdadeiro exercício de futurologia -, representa, de fato, séria ameaça à segurança jurídica dos cidadãos e à autonomia operacional de todo o sistema jurídico, cuja hierarquia normativa resta vilipendiada, de modo que se revela manifestamente inconstitucional.

Se, todavia, as consequências práticas, a que se refere o artigo 20, devem ser compreendidas como sendo nada mais do que os resultados lógicos da aplicação do Direito, então a alteração legislativa em questão mostra-se redundante, porquanto não faz senão conformar-se ao que a ordem jurídico-constitucional desde há muito pressupõe; a saber, o compromisso do Poder Judiciário para com a segurança jurídica, para a qual não contribui o consequencialismo, segundo a Constituição de 1988 (MARTINS, 2019, p. 2019), e sem a qual não pode haver a concretização da justiça nem o desenvolvimento nacional.

\section{REFERÊNCIAS}

ARAÚJO, Thiago Cardoso. Análise Econômica do Direito no Brasil: uma leitura à luz da Teoria dos Sistemas. Rio de Janeiro: Lumen Juris, 2017.

ÁVILA, Humberto. Argumentação jurídica e a imunidade do livro eletrônico. In: TORRES, Ricardo Lobo (coord.). Temas de Interpretação do Direito Tributário. V. 1. Rio de Janeiro: Renovar, 2003. p. 109-157.

ÁVILA, Humberto. Legalidade Tributária Multidimensional. In: FERRAZ, Roberto (coord.). Princípios e Limites da Tributação. V. 1. São Paulo: Quartier Latin, 2005. p. 277-291.

ÁVILA, Humberto. Teoria da Segurança Jurídica. 4. ed. São Paulo: Malheiros Editores, 2016.

BALEEIRO, Aliomar. Direito Tributário Brasileiro. Atualizada por Misabel Abreu Machado Derzi. 12. ed. Rio de Janeiro: Forense, 2013.

BALEEIRO, Aliomar. Limitações constitucionais ao poder de tributar. Atualizada por Misabel Abreu Machado Derzi. 8. ed. Rio de Janeiro: Forense, 2010.

BARROSO, Luís Roberto. Curso de direito constitucional contemporâneo: os conceitos fundamentais e a construção do novo modelo. 7. ed. São Paulo: Editora Saraiva, 2018.

BECKER, Alfredo Augusto. Teoria Geral do Direito Tributário. 7. ed. São Paulo: Noeses, 2018. 
BERNARDES, Flávio Couto. O aspecto procedimental como elemento da norma jurídica tributária e seus reflexos na formação do título executivo. 2006. $461 \mathrm{f}$. Tese (Doutorado em Direito) - Faculdade de Direito, Universidade Federal de Minas Gerais, Belo Horizonte, 2006.

BILHIM, Renata da Silveira. Pragmatismo e Justificação da Decisão Judicial: a argumentação consequencialista como fundamento de validade da justa decisão. 1. ed. Rio de Janeiro: Lumen Juris, 2016.

BRASIL. Constituição da República Federativa do Brasil - 1988. Diário Oficial da União, Brasília, DF, 5 out. 1988. Disponível em: http://bit.ly/36g9gGM. Acesso em: 10 maio 2019.

BRASIL. Lei $\mathrm{n}^{0}$ 13.655, de 25 de abril de 2018. Inclui no Decreto-Lei $\mathrm{n}^{\circ}$ 4.657, de 4 de setembro de 1942 (Lei de Introdução às Normas do Direito Brasileiro), disposições sobre segurança jurídica e eficiência na criação e na aplicação do direito público. Diário Oficial da União, Brasília, DF, 26 abr. 2018. Disponível em: http://bit.ly/2rtRGAn. Acesso em: 10 maio 2019.

CARRAZZA, Roque Antonio. Curso de Direito Constitucional Tributário. 30. ed. São Paulo: Malheiros Editores, 2015.

CARVALHO, Paulo de Barros. Direito Tributário: linguagem e método. 6. ed. São Paulo: Noeses, 2015.

COÊLHO, Sacha Calmon Navarro. Curso de Direito Tributário Brasileiro. 14. ed. Rio de Janeiro: Forense, 2015.

COÊLHO, Sacha Calmon Navarro. O controle de constitucionalidade das leis e o poder de tributar na CF/1988. 4. ed. Rio de Janeiro: Forense, 2016.

CRUZ, Álvaro Ricardo de Souza; DUARTE, Bernardo Augusto Ferreira. Além do positivismo jurídico. Belo Horizonte: Arraes, 2013.

CRUZ, Álvaro Ricardo de Souza; SALDANHA, Fernanda Monteiro. Por uma interpretação não utilitarista do Direito. In: CRUZ, Álvaro Ricardo de Souza (coord.). (O) outro (e) (o) direito. Belo Horizonte: Arraes, 2015. p. 52-113.

DIMOULIS, Dimitri. Positivismo jurídico: teoria da validade e da interpretação do direito. 2. ed. Porto Alegre: Livraria do Advogado, 2018.

FOLLONI, André; SIMM, Camila Beatriz. Direito Tributário, complexidade e análise econômica do direito. Revista Eletrônica do Curso de Direito da UFSM, v. 11, n. 1, p. 49-70, 2016. Disponível em: http://bit.ly/352YeVi. Acesso em: 10 maio 2019.

GODOI, Marciano Seabra de. O consequencialismo e as modulações dos efeitos das decisões do STF. In: ROCHA, Valdir de Oliveira (coord.). Grandes Questões Atuais do Direito Tributário. V. 13. São Paulo: Dialética, 2009. p. 286-320.

KELSEN, Hans. Teoria Pura do Direito. Tradução João Baptista Machado. 7. ed. São Paulo: Martins Fontes, 2006. 
LUHMANN, Niklas. O direito da sociedade. Tradução Saulo Krieger e Alexandre Agnolon. São Paulo: Martins Fontes, 2016.

LUQUE, Carlos Antonio. Em busca da solução de conflitos: lógica econômica x direito. In: MARTINS, Ives Gandra da Silva et al. Consequencialismo no Poder Judiciário. Indaiatuba: Foco, 2019. p. 137-144.

MACCORMICK, Neil. Rhetoric and the Rule of Law: A Theory of Legal Reasoning. 1st ed. Oxford: Oxford University Press, 2005.

MACHADO, Hugo de Brito. Teoria Geral do Direito Tributário. São Paulo: Malheiros, 2015.

MARTINS, Ives Gandra da Silva. Consequencialismo jurídico e a Constituição de 1988. In: MARTINS, Ives Gandra da Silva et al. Consequencialismo no Poder Judiciário. Indaiatuba: Foco, 2019. p. 17-28.

MATHIS, Klaus. Consequentialism in Law. In: MATHIS, Klaus (ed.). Efficiency, Sustainability and Justice for Future Generations. Law and Philosophy Library, v. 98. Dordrecht: Springer, 2012. p. 3-29.

MINDA, Gary. Postmodern Legal Movements: Law and Jurisprudence at Century's End. New York: New York University Press, 1995.

NEVES, Marcelo. Entre Têmis e Leviatã: uma relação difícil: o Estado Democrático de Direito a partir e além de Luhmann e Habermas. Tradução Marcelo Neves. 1. ed. São Paulo: Martins Fontes, 2006.

NOBLES, Richard; SCHIFF, David. A Sociology of Jurisprudence. Oxford: Hart Publishing, 2006.

PAULSON, Stanley L. Kelsen on legal interpretation. Legal Studies, V. 10, I. 2, p. 136-152, July 1990.

PISCITELLI, Tathiane dos Santos. Argumentando pelas consequências no Direito Tributário. São Paulo: Noeses, 2011.

POSNER, Richard. Law, Pragmatism and Democracy. Cambridge: Harvard University Press, 2003.

ROCHA, Sergio André. Modulação de efeitos da decisão de inconstitucionalidade e consequencialismo: instrumentos de desconstitucionalização do Direito Tributário. In: COÊLHO, Sacha Calmon Navarro (coord.). Segurança Jurídica: irretroatividade das decisões judiciais prejudiciais aos contribuintes. Rio de Janeiro: Forense, 2013. p. 187-194.

SCHOUERI, Luís Eduardo. Direito Tributário. 8. ed. São Paulo: Editora Saraiva, 2018.

SHECAIRA, Fábio P; STRUCHINER, Noel. Teoria da argumentação jurídica. Rio de Janeiro: Contraponto, 2016. 
SILVEIRA, Paulo Antônio Caliendo Velloso da. Direito Tributário e análise econômica do Direito: uma visão crítica. Rio de Janeiro: Elsevier, 2009.

TORRES, Heleno Taveira. Direito Constitucional Tributário e Segurança Jurídica: metódica da segurança jurídica do Sistema Constitucional Tributário. São Paulo: Revista dos Tribunais, 2011.

TORRES, Ricardo Lobo. O consequencialismo e a modulação dos efeitos das decisões do Supremo Tribunal Federal. In: DERZI, Misabel Abreu Machado (coord.). Separação de poderes e efetividade do sistema tributário. Belo Horizonte: Del Rey, 2010. p. 19-50.

VERMEULE, Adrian. Judging under uncertainty: an institutional theory of legal interpretation. Cambridge: Harvard University Press, 2006.

VIARO, Felipe Albertini Nani. Consequencialismo e Decisão Judicial. In: MARTINS, Ives Gandra da Silva et al. Consequencialismo no Poder Judiciário. Indaiatuba: Foco, 2019. p. 73-86.

VILANOVA, Lourival. As Estruturas Lógicas e o Sistema de Direito Positivo. 4. ed. São Paulo: Noeses, 2010.

VILANOVA, Lourival. Causalidade e Relação no Direito. 5. ed. São Paulo: Noeses, 2015.

Flávio Couto Bernardes Doutor, Mestre e Bacharel em Direito pela Faculdade de Direito da Universidade Federal de Minas Gerais. Professor na Universidade Federal de Minas Gerais e na Pontifícia Universidade Católica de Minas Gerais. Procurador do Município de Belo Horizonte e advogado.E-mail: flavio.bernardes@bernardesadvogados.adv.br

Vinícius Simões Borges Espinheira Fonseca Mestrando em Direito Público pela Pontifícia Universidade Católica de Minas Gerais. Bacharel em Direito pela Faculdade de Direito da Universidade Federal de Minas Gerais. Advogado. E-mail: espinheirafonseca@gmail.com 